\title{
Exercise and Sarcopenia in Cirrhosis
}

\author{
Jonathan Soldera ${ }^{1 *}$, Anderson $\operatorname{Rech}^{2}$ and Danusa Rossi ${ }^{3}$ \\ 1Department of Gastroenterology, Universidade de Caxias do Sul, Brazil
}

2Department of Human Movement Sciences, Universidade Federal do Rio Grande do Sul, Brazil

3Department of Hepatology, Universidade Federal de Ciências da Saúde de Porto Alegre, Brazil

*Corresponding author: Jonathan Soldera, Associate professor of Gastroenterology, Universidade de Caxias do Sul, Vereador Mário Pezzi Avenue, 699/601, Caxias do Sul-RS, Brazil

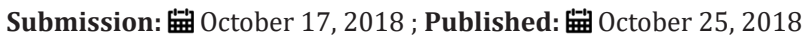

\section{Editorial}

Cirrhosis is the end stage of every chronic liver disease, which leads to fibrosis and inflammation, resulting in a compromise of the structure and function of the liver [1]. Cirrhosis can cause a collapse of liver histology, modifying the vascular architecture of the organ and increasing the risk of cancer [2]. Besides the obvious consequences regarding the physiological function of the liver, cirrhosis might affect other tissues indirectly, like the muscular tissue. These patients might present a sensible loss of muscular mass, leading to clinically significant sarcopenia $[3,4]$.

Sarcopenia in cirrhosis has been associated to lower survival, although some degree of recuperation after liver transplantation has been described [5-7]. It is present in around $40 \%$ of patients listed for liver transplantation and it doubles the risk of death in the waiting list [5]. This risk has been associated to sarcopenia independently of MELD scores [8]. Even though many factors linked to muscular disease in cirrhotic patients are not yet completely understood, it is believed that this condition impairs muscular homeostasis, leading to an imbalance between synthesis and consumption of muscular proteins, which might in turn cause accelerated and intense loss of muscular mass [9]. Such sarcopenia is believed to be the most important cause of functional incapacity, malnutrition and dependence $[4,9]$.

Functional impairment caused (or intensified) by sarcopenia might worsen the health condition of these patients, reducing their levels of daily physical activity, leading to an underuse of the muscular system, increasing the waste of muscular mass. Physical performance tests, such as the 6-minute walk test and oxygen consumption, have also been shown to be useful into predicting mortality in this population, suggesting that physical inactivity might be an important marker for treatment and follow-up of this condition $[10,11]$. Many studies in other populations suggest that the production of force and muscular potency as main determinants of functional capacity [12-14].

Force training has been widely suggested as an important modality of treatment for sarcopenia [15-19]. Although there are only a few studies which can shed some light into this question, it is known that the use of force is impaired in cirrhotic patients, which generally varies according to the disease stage [20]. Recently, some papers have suggested that rehabilitation programs for these patients should be aimed into increasing force to combat sarcopenia, which could improve prognosis and quality of life in cirrhotic patients, improving clinical outcomes such as hepatic encephalopathy [21,22]. Although some strategies for physical exercise might have been already tested [21-24], no studies that uses force training in cirrhotic patients has been found, specially randomized trials. Hence force training is a valuable tool in the slowing of sarcopenia $[25,26]$, in the increasing of muscular force $[27,28]$, functionality [29-31] and quality of life [19,30,32], studies which could use this modality of exercise in the treatment of this population are needed.

In conclusion, sarcopenia is considered currently an important complication of cirrhosis, which worsens functionality and affect outcomes. A randomized clinical trial of force training for the treatment of sarcopenia in cirrhosis is long awaited to clarify this problem..

\section{References}

1. Nishikawa H, Osaki Y (2015) Liver cirrhosis: evaluation, nutritional status and prognosis. Mediators Inflamm 2015: 872152.

2. Poordad FF (2015) Presentation and complications associated with cirrhosis of the liver. Curr Med Res Opin 31(5): 925-937.

3. Kallwitz ER (2015) Sarcopenia and liver transplant: The relevance of too little muscle mass. World J Gastroenterol 21(39): 10982-10993.

4. Kim HY, Jang JW (2015) Sarcopenia in the prognosis of cirrhosis: Going beyond the MELD score. World J Gastroenterol 21(25): 7637-7647.

5. Montano-Loza AJ (2013) New concepts in liver cirrhosis: clinical significance of sarcopenia in cirrhotic patients. Minerva Gastroenterol Dietol 59(2): 173-186.

6. Montano-Loza AJ, Meza-Junco J, Prado CM, Lieffers JR, Baracos VE, et al. (2012) Muscle wasting is associated with mortality in patients with cirrhosis. Clin Gastroenterol Hepatol 10(2): 166-173.

7. Kalafateli M, Konstantakis C, Thomopoulos K, Triantos C (2015) Impact of muscle wasting on survival in patients with liver cirrhosis. World J Gastroenterol 21(24): 7357-7361. 
8. Durand F, Buyse S, Francoz C, Laouénan C, Bruno O, et al. (2014) Prognostic value of muscle atrophy in cirrhosis using psoas muscle thickness on computed tomography. J Hepatol 60(6): 1151-1157.

9. Periyalwar P, Dasarathy S (2012) Malnutrition in cirrhosis: contribution and consequences of sarcopenia on metabolic and clinical responses. Clin Liver Dis 16(1): 95-131.

10. Galant LH, Forgiarini Junior LA, Dias AS, Marroni CA (2012) Functional status, respiratory muscle strength, and quality of life in patients with cirrhosis. Rev Bras Fisioter 16(1): 30-34

11. Faustini Pereira JL, Galant LH, Rossi D, Telles da Rosa LH, Garcia E, et al. (2016) Functional Capacity, Respiratory Muscle Strength and Oxygen Consumption Predict Mortality in Patients with Cirrhosis. Can J Gastroenterol Hepatol 2016: 6940374.

12. Porter MM (2006) Power training for older adults. Appl Physiol Nutr Metab 31(2): 87-94.

13. Rech A, Radaelli R, Goltz FR, da Rosa LH, Schneider CD, et al. (2014) Echo intensity is negatively associated with functional capacity in older women. Age (Dordr) 36(5): 9708.

14. Wilhelm EN, Rech A, Minozzo F, Radaelli R, Botton CE, et al. (2014) Relationship between quadriceps femoris echo intensity, muscle power, and functional capacity of older men. Age (Dordr) 36(3): 9625.

15. Aguirre LE, Villareal DT (2015) Physical exercise as therapy for frailty. Nestle Nutr Inst Workshop Ser 83: 83-92.

16. Makanae Y, Fujita S (2015) Role of Exercise and Nutrition in the Prevention of Sarcopenia. J Nutr Sci Vitaminol (Tokyo) 61 Suppl: S125-S127.

17. Csapo R, Alegre LM (2016) Effects of resistance training with moderate vs heavy loads on muscle mass and strength in the elderly: A metaanalysis. Scand J Med Sci Sports 26(9): 995-1006.

18. Ciolac EG, Rodrigues-da-Silva JM (2016) Resistance training as a tool for preventing and treating musculoskeletal disorders. Sports Med 46(9): 1239-1248.

19. Papa EV, Dong X, Hassan M (2017) Resistance training for activity limitations in older adults with skeletal muscle function deficits: systematic review. Clin Interv Aging 12: 955-961.

20. Krüger RL, Teixeira BC, Dias AS, Reischak-Oliveira A (2015) The influence that hepatic cirrhosis provides in exercise capacity and muscle strength: a review. Fisioterapia em Movimento 28(3): 617-625.
21. Román E, Torrades MT, Nadal MJ, Cárdenas G, Nieto JC, et al. (2014) Randomized pilot study: effects of an exercise programme and leucine supplementation in patients with cirrhosis. Dig Dis Sci 59(8):19661975.

22. Trivedi HD, Tapper EB (2018) Interventions to improve physical function and prevent adverse events in cirrhosis. Gastroenterol Rep (Oxf) 6(1): $13-20$

23. Zenith L, Meena N, Ramadi A, Yavari M, Harvey A, et al. (2014) Eight weeks of exercise training increases aerobic capacity and muscle mass and reduces fatigue in patients with cirrhosis. Clin Gastroenterol Hepatol 12(11): 1920-1926.

24. Román E, García-Galcerán C, Torrades T, Herrera S, Marín A, et al. (2016) Effects of an exercise programme on functional capacity, body composition and risk of falls in patients with cirrhosis: A randomized clinical trial. PLoS One 11(3): e0151652.

25. Seguin R, Nelson ME (2003) The benefits of strength training for older adults. Am J Prev Med 25(3 Suppl 2): 141-149.

26. Haran PH, Rivas DA, Fielding RA (2012) Role and potential mechanisms of anabolic resistance in sarcopenia. J Cachexia Sarcopenia Muscle 3(3): 157-162.

27. Bouchard DR, Janssen I (2010) Dynapenic-obesity and physical function in older adults. J Gerontol A Biol Sci Med Sci 65(1): 71-77.

28. Radaelli R, Botton CE, Wilhelm EN, Bottaro M, Lacerda F, et al. (2013) Low- and high-volume strength training induces similar neuromuscular improvements in muscle quality in elderly women. Exp Gerontol 48(8): 710-716.

29. Macaluso A, De Vito G (2004) Muscle strength, power and adaptations to resistance training in older people. Eur J Appl Physiol 91(4): 450-472.

30. Hunter GR, McCarthy JP, Bamman MM (2004) Effects of resistance training on older adults. Sports Med 34(5): 329-348.

31. Barry BK, Carson RG (2004) The consequences of resistance training for movement control in older adults. J Gerontol A Biol Sci Med Sci 59(7): 730-754.

32. Lopez P, Radaelli R, Rech A, Wilhelm EM, Pinto RS (2015) Muscle quality, but not muscle thickness, is decreased in different age groups of active older women. Revista Brasileira de Cineantropometria \& Desempenho Humano 17(3): 347-356
Creative Commons Attribution 4.0

International License

For possible submissions Click Here

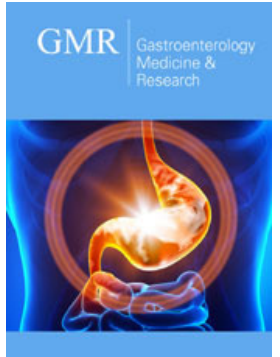

\section{Gastroenterology Medicine \& Research}

\section{Benefits of Publishing with us}

- High-level peer review and editorial services

- Freely accessible online immediately upon publication

- Authors retain the copyright to their work

- Licensing it under a Creative Commons license

- Visibility through different online platforms 